\title{
A ética protestante e a formação de um ethos esportivo
}

\author{
Naraỵana Astra van Amstel' \\ Leonardo do Couto Gomes² \\ Marcelo Moraes e Silva ${ }^{3}$
}

\section{RESUMO}

A presente resenha retrata a obra de Steven Overman, denominada "The Protestant Ethic and the Spirit of Sport: How Calvinism and Capitalism Shaped America's Games". Sob linhagem teórica weberiana e com influência direta de Allen Guttmann, o autor resgata as doutrinas puritanas do período reformista, como consequência e causa do espírito capitalista americano. Ao propor as sete virtudes calvinistas como características essenciais da ética protestante, Overman demonstra como as mesmas culminaram no establishment das instituições americanas, inclusive as relacionadas à esfera esportiva. Ao relacionar as virtudes e doutrinas oriundas da reforma no ethos americano, o autor identifica suas correspondências no espírito do esporte, demonstrando como competições escolares e universitárias, o olimpismo moderno e a profissionalização de clubes e atletas, comungam com o capitalismo e protestantismo nos EUA.

Palavras-chave: Capitalismo. Protestantismo. Esporte

1 Mestrando em Educação Física pela Universidade Federal do Paraná (UFPR). Curitiba/Paraná, Brasil. E-mail: narayana.astra@gmail.com

2 Graduando em Educação Física pela Universidade Federal do Paraná (UFPR). Curitiba/Paraná, Brasil. E-mail: leo_gomes.97@hotmail.com

3 Doutor em Educação. Professor do Departamento de Educação Física e do Programa de Pós-Graduação em Educação Física na Universidade Federal do Paraná (UFPR). Curtiba/Paraná, Brasil. E-mail: moraes_marc@ yahoo.com.br

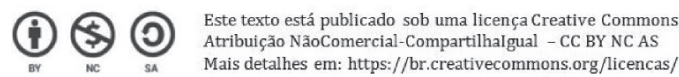


The protestant ethic and the formation of a sporting ethos

\begin{abstract}
The present review depicts Steven Overman's book "Protestant Ethic and the Spirit of Sport: How Calvinism and Capitalism Shaped America's Games." Under Weberian theoretical lineage and with direct influence of Allen Guttmann, the author sees puritan doctrines of the reformist period as both consequence and cause of the American spirit of capitalism. By proposing seven Calvinistic virtues as essential features of Protestant ethic, Overman demonstrates how they culminated in the establishment of American institutions, including those related to the sphere of sport. By relating virtues and doctrines coming from the reform in the American ethos, the author identifies his correspondences in the spirit of sport, demonstrating how school and college competitions, the Olympic movement and the professionalization of clubs and athletes commune with the USA's capitalism and Protestantism.
\end{abstract}

Keywords: Capitalism. Protestantism. Sport

La ética protestante y la formación de un ethos deportivo

\title{
RESUMEN
}

La presente reseña retrata la obra de Steven Overman, denominada "The Protestant Ethic and the spirit of sport: How calvinism and capitalism shaped America's Games". En linaje teórica weberiana y con influencia directa de Allen Guttmann, el autor rescata las doctrinas puritanas del período reformista como consecuencia y causa del espíritu capitalista americano. Al proponer las siete virtudes calvinistas como características esenciales de la ética protestante, Overman demuestra cómo las mismas culminaron en el establishment de las instituciones americanas incluso las relacionadas a la esfera deportiva. Al relacionar las virtudes y doctrinas oriundas de la reforma en el ethos americano el autor identifica sus correspondencias en el espíritu del deporte, demostrando como competiciones escolares y universitarias, el olimpismo moderno y la profesionalización de clubes y atletas, comulgan con el capitalismo y protestantismo de Estados Unidos.

Palabras-clave: Capitalismo. Protestantismo. Deporte

Apontar características de uma ética protestante no espírito do esporte moderno, especificamente no cenário dos Estados Unidos da América, foi o que buscou Steven Overman em seu livro The Protestant Ethic and the Spirit of Sport: How Calvinism and Capitalism Shaped America's Games. O autor, natural de Lafayette, Indiana (EUA), formou-se 
pela Purdue University (EUA) e realizou seu doutorado na Washington State University (EUA). Passou a maior parte de sua carreira docente de 35 anos na Jackson State University (EUA), no estado do Mississippi, aonde se aposentou em 2005. Suas diversas obras têm por principal característica a tematização do esporte em uma perspectiva crítica.

A obra, que não possui tradução na língua portuguesa, foi inspirada no pensamento dos sociólogos Max Weber e Allen Guttmann, traçando a forma como ocorreu a migração da ideologia protestante do velho para o novo mundo. Para isso, o autor explica as origens históricas do movimento protestante no contexto europeu, dando ênfase nos movimentos puritanos e calvinistas do século XVI. Tudo objetivando compreender a formação de um espírito capitalista (no sentido weberiano) para então estabelecer uma relação direta desse modus operandi religioso com a ascensão do esporte moderno no mundo ocidental, sobretudo nos Estados Unidos da América.

A obra, segundo o prefácio do autor, é uma evolução de um texto anterior, denominado The influence of the protestant ethic on sport and recreation ${ }^{4}$. Contudo, no livro foram acrescentados os seguintes aspectos: depoimentos de atletas, um aprofundamento na análise da cultura americana, perpassando por temas como a mercantilização e profissionalização do esporte de participação, colegial e universitário, institucionalização do esporte infanto-juvenil e a apropriação do esporte de rendimento pelo capitalismo corporativista.

O livro é dividido em duas partes: a primeira, The protestant ethic, composta de 6 capítulos, aborda a origem, características e legado do protestantismo, bem como um detalhamento das consideradas virtudes protestantes e sua influência no ethos americano. A segunda parte, The spirit of sport, composta de sete capítulos, trata das relações entre o esporte americano e a ética protestante, investigando desde a institucionalização das práticas esportivas, passando pelo esporte na infância e juventude americana, bem como o perfil do esporte amador e profissional no contexto protestante.

O autor abre sua introdução apontando as quatro principais questões que norteiam a discussão do livro: 1) Por que americanos sentem-se culpados quando estão se divertindo? 2) Por que infundem propósitos morais em jogos? 3) Por que transformaram esportes em atividades racionalizadas, visando metas carregadas de uma lógica de trabalho? 4) Por que vencer se tornou tão importante para essa nação?

The legacy of puritanism é o título do segundo capítulo, no qual demonstra como aspectos próprios do calvinismo e do puritanismo inglês marcaram o pensamento americano: a) crença na predestinação da salvação; b) vocação para o serviço divino, agora manifesta no trabalho mundano e não apenas no sacerdócio, como entre os católicos; e c) prosperidade material como indicativo de graça divina.

O terceiro capítulo, The protestant ethic and the spirit of american capitalism, explora a ideia de Max Weber de que o protestantismo teve um papel fundamental em propiciar espírito político e moral condizentes com a ascensão do capitalismo. Entretanto, uma análise mais aprofundada do livro resenhado demonstrou que essa relação foi, na 
opinião do autor, mais de mútua dependência do que de causa e efeito, pois não necessariamente o protestantismo gerou o capitalismo e vice-versa.

No quarto capítulo, intitulado The seven protestant virtues, o autor faz uma alusão às virtudes cardeais do pensamento aristotélico de São Tomás de Aquino, esboçando sete valores, comportamentos e crenças comuns ao protestantismo, que resumem a ética que deu embasamento para a origem da lógica capitalista e posteriormente sua materialização no espírito do esporte: 1) ascetismo mundano, no qual a abstinência medieval, quase que exclusiva das ordens monásticas, foi substituída por uma praticada por toda a comunidade protestante; 2) racionalização, que precisava ser estendida para todas as instituições sociais (estabelecido no meio militar inglês por Oliver Cromwel; na conduta moral americana, enfatizada por Benjamin Franklin; e na divisão do trabalho em fábricas, encontrado na importante obra "A Riqueza das Nações" do economista escocês Adam Smith); 3) estabelecimento de metas, de forma que todas as ações tomadas pelo indivíduo protestante precisavam comungar com a meta final de salvação pessoal; 4) autorrealização no mundo material, em que, por meio da crença na predestinação da salvação, se esforçavam no caminho vocacional, demonstrariam progresso no plano terreno, e garantiriam a vitória na alçada espiritual; 5) individualismo, em que a formação estamental dos grupos sociais no medievo foi gradualmente substituída pelo coletivo de indivíduos únicos e responsáveis por seu próprio destino. Afinal, teologicamente, a extinção de intermediários entre o Céu e a Terra exigia a manifestação do "Eu" como único determinante do sucesso espiritual; 6) ética de trabalho, em que os afazeres da vida rural medieval, tradicionalmente sazonais, a visão greco-romana de trabalho como sofrimento e de associação às classes escravizadas e estrangeiras, e a visão católica medieval de serviços espirituais bons e obrigações mundanas ruins foram gradualmente substituídos na cultura protestante por uma valorização do trabalho secular para todos os grupos sociais; e 7) ética de controle do tempo, momento de ter domínio do espaço (próprio corpo, estabelecimento comercial e da cidade) e do crono. Assim, atribuiu-se três imperativos morais ao tempo: que ele é bom, que deve ser preenchido com atividades produtivas e que todas as ações devem ser realizadas visando o futuro.

Protestantism and the american ethos é o tema explorado no quinto capítulo e apresenta o poder da cultura protestante na formação do ethos americano. Aborda desde a chegada dos primeiros navios de colonizadores puritanos da Inglaterra; tematiza a abertura de inúmeras instituições educacionais protestantes; exalta que a maioria dos Pais Fundadores eram protestantes; indica ainda que houve uma exclusividade de presidentes protestantes nos EUA até 1961 com a subida ao poder de um católico, John Kennedy; salienta o processo de assimilação da ética protestante por imigrantes italianos, alemães, ingleses, asiáticos e outras tantas culturas que adentram o país e, por fim, aponta o american dream como representação dos valores protestantes. Para Overman, a classe média americana é a representante ideal do protestantismo, pois é um grupo social que abraça tanto a ética protestante quanto o espírito do capitalismo. Contudo, pela forma como a estrutura econômica do país permite uma alta mobilidade social, o autor aponta que existe na nação uma mentalidade de que as diferenças são quase que inexistentes. Assim, o americam dream pode ser imaginado e desejado por todos. 
O sexto capítulo, The evolution of the american work ethic, mostra como o utilitarismo e o pragmatismo foram elementos marcantes na ética de trabalho entre os protestantes e como mudanças causadas pelas revoluções industriais modificaram esse quadro. Inicialmente, na opinião do autor, existiam quatro componentes comuns no pensamento calvinista: 1) fé no trabalho como um ato criativo; 2) necessidade da ocupação ser útil; 3) medo da ociosidade; e 4) o trabalho como caminho para salvação e prosperidade no mundo secularizado. Posteriormente, o trabalho industrial, aos poucos, criou sentimentos de isolamento, perda de identidade e substituição da ideia luterana de vocação para a de um simples emprego. Nesse momento, Overman recorre à teoria marxista de alienação no serviço industrial, para mostrar as mudanças que a ética protestante de trabalho sofreu num contexto norte-americano.

The protestant ethic and the institutionalization of american sport é o título do sétimo capítulo, que abre a segunda parte do livro, momento no qual o autor perpassa a cultura de classe média, a racionalização exacerbada, as comunidades religiosas como organizadoras dos divertimentos de seus membros e a filosofia do cristianismo muscular, que promoveram a associação do esporte a outras instituições consolidadas na sociedade, tais como a família, a escola e o governo. A relação com a pátria é exemplificada pelo canto do hino nacional e o hastear da bandeira dos EUA antes de cada partida. Na esfera política, o presidente arremessa a primeira bola de baseball na abertura de cada temporada. Nas instituições religiosas, a Associação Cristã de Moços, por muito tempo, foi a entidade máxima na organização dos divertimentos de jovens cristãos, tanto nos EUA como em outros países.

Os capítulos seguintes são intitulados The american sports ethics: 1 \& 2, e esmiúçam, conjuntamente, as manifestações, dentro do esporte, das sete virtudes protestantes apresentadas no capítulo 4. Segundo o autor, os valores esportivos e as virtudes protestantes apresentam forte ligação. Por exemplo, ambos apresentam códigos de comportamento reforçados por rituais, possuem um sistema de crenças adotado e internalizado por seus praticantes e exercem coesão e controle de indivíduos.

O décimo capítulo, Child-rearing and youth sport in protestant culture, investiga como o esporte infanto-juvenil teve suas características moldadas pela família protestante nos EUA: iniciação precoce nas modalidades esportivas; o fator socializante do esporte dentro das famílias, bem como entre elas; o uso do esporte como formador de caráter e ferramenta para afastar a juventude da preguiça e outros maus hábitos.

The co-opting of amateur sport é o tema discutido no décimo primeiro capítulo. Nesse momento o autor expõe como as forças do profissionalismo e mercantilismo convergiram para formar um ethos específico no amadorismo americano, influenciando os segmentos do esporte recreacional, colegial, universitário e olímpico. Apesar do amadorismo original ser britânico e próprio da nobreza, sua influência nos EUA não foi duradoura, visto que os clubes americanos, no desejo pela vitória e por uma maior fluidez entre as classes sociais, facilitaram a entrada de atletas de diferentes grupos. As equipes americanas, que formavam estruturas para treinamento e competição, necessitavam de renda para manutenção, o que tornou natural o aluguel dos espaços (quando não utilizados) ou a cobrança de entradas para 
espectadores, algo que não ocorreu na mesma velocidade no território britânico. Houve também a facilitação da profissionalização nas modalidades mais populares, tais como o beisebol e o boxe, e uma dificuldade maior em esportes elitistas, como o golfe e o pólo. Um possível fator da profissionalização acentuada foi a necessidade de cada vez maior dedicação dos atletas para obter rendimento em provas cada vez mais exigentes; tornava-se inviável manter um emprego e ao mesmo tempo disputar uma final de campeonato sustentando uma qualidade técnica elevada. Com o tempo, o termo "profissional" perdeu sua conotação pejorativa e passou a ser visto como exemplo positivo. Já um atleta amador é associado a uma pessoa que não possui habilidade e compromisso adequados ao esporte.

No décimo segundo capítulo, Professional sport: the progeny of capitalism, Overman versa sobre o esporte como uma área integrante no contexto do capitalismo, por dar suporte e crescimento para diversas empresas. As franquias esportivas, os torcedores, o licenciamento de produtos, a cobertura da mídia, o uso de marketing durante megaeventos e o surgimento de uma ética de gerenciamento dentro dos clubes profissionais dão embasamento para o autor estabelecer um casamento teórico entre o esporte e o capitalismo.

Finish line: summing up the ethos of sport é o décimo terceiro e último capítulo da obra, onde retoma-se a ideia central que já dava título ao livro: quando valores culturais adentram o campo esportivo, passam a ter poder para modificá-lo. Nesse momento da obra Overman mostra seu aporte de teórico crítico e, após quatrocentas páginas de pesquisas em fontes diversas, resolve demonstrar sua opinião valorativa sobre o espírito do esporte americano moldado pelo protestantismo. O autor deixa claro que o pessimismo é a melhor alternativa de pensamento após o vislumbre da temática apresentada. Overman acredita que o esporte se tornou uma imitação desagradável do trabalho e um instrumento de marketing na máquina capitalista. Numa tentativa, em certo sentido romântica, de apresentar uma solução para o esporte moderno, sugere que a sociedade retome brincadeiras e jogos que tenham como meio e finalidade o prazer. Defende o abandono de metas, o desapego das audiências, espectadores e a competição que deseja apenas o senso de excelência nos limites humanos. Resumidamente, um retorno às práticas amadoras, porém sem definir em que momento da história de fato existiu o amadorismo perfeito para todos os grupos sociais desfrutarem do esporte.

A título de considerações finais sobre o livro resenhado, observa-se que a leitura dessa obra nos convida a repensar, de maneira criteriosa e aprofundada, se o esporte é um elemento autônomo dentro da sociedade, como os seus idealizadores no final do século XIX e início do XX desejavam que fosse, exemplificados por Overman principalmente na figura de Pierre de Coubertin.

The Protestant Ethic and the Spirit of Sport: How Calvinism and Capitalism Shaped America's Games é um texto rico em fontes e argumentos no que propõe discutir. A união do pensamento sociológico com a História e a Teologia não é algo inédito, mas ainda demonstra eficiência quando dialogada com propriedade e aprofundamento. Se o protestantismo e o capitalismo têm um papel na formação do espírito do esporte americano, abrem-se questionamentos sobre a possível influência de outras culturas religiosas, tais como o catolicismo brasileiro e italiano, bem como o ateísmo chinês e soviético, no tocante 
ao esporte. As relações, ora conflituosas, ora harmoniosas, entre virtudes e pecados, entre ética e moral, entre as atividades sacras e mundanas, possibilita aos pesquisadores que se interessarem por tais temáticas compreenderem melhor como indivíduos, com suas crenças pertencentes à esfera do sagrado, acabam também por transformar o mundo material.

Considera-se a obra resenhada uma importante contribuição para os estudos de perspectiva antropológica, filosófica, histórica e sociológica em relação ao esporte, potencializando discussões acerca de aspectos culturais, religiosos e econômicos, que podem ser aplicados ao contexto da pesquisa em Educação Física e Esporte no Brasil e em outros países da América Latina.

\section{REFERÊNCIA}

OVERMAN, Steven. The Protestant Ethic and the Spirit of Sport: How Calvinism and Capitalism Shaped America's Games. Macon, GA: Mercer University Press, 423p., 2011.

Recebido em: Outubro/2017

Aprovado em: Maio/2018 